Article

\title{
Development of Recyclable and High-Performance In Situ Hybrid TLCP/Glass Fiber Composites
}

\author{
Tianran Chen ${ }^{1, *} \mathbb{C}$, Dana Kazerooni ${ }^{1}$, Lin Ju ${ }^{1}$, David A. Okonski ${ }^{2}$ and Donald G. Baird ${ }^{1,3}$ \\ 1 Macromolecules Innovation Institute, Virginia Tech, Blacksburg, VA 24061, USA; dk4z@vt.edu (D.K.); \\ linj7@vt.edu (L.J.); dbaird@vt.edu (D.G.B.) \\ 2 GM Global Research \& Development Center, Warren, MI 48092, USA; david.a.okonski@gm.com \\ 3 Department of Chemical Engineering, Virginia Tech, Blacksburg, VA 24061, USA \\ * Correspondence: tianran@vt.edu
}

Received: 26 July 2020; Accepted: 19 August 2020; Published: 24 August 2020

\begin{abstract}
By combining the concepts of in situ thermotropic liquid crystalline polymer (TLCP) composites and conventional fiber composites, a recyclable and high-performance in situ hybrid polypropylene-based composite was successfully developed. The recycled hybrid composite was prepared by injection molding and grinding processes. Rheological and thermal analyses were utilized to optimize the processing temperature of the injection molding process to reduce the melt viscosity and minimize the degradation of polypropylene. The ideal temperature for blending the hybrid composite was found to be $305^{\circ} \mathrm{C}$. The influence of mechanical recycling on the different combinations of TLCP and glass fiber composites was analyzed. When the weight fraction ratio of TLCP to glass fiber was 2 to 1 , the hybrid composite exhibited better processability, improved tensile performance, lower mechanical anisotropy, and greater recyclability compared to the polypropylene reinforced by either glass fiber or TLCP alone.
\end{abstract}

Keywords: recycling; hybrid composites; polymer-matrix composites (PMCs); thermotropic liquid crystalline polymer; glass fibers

\section{Introduction}

The early constructions of vehicles like automobiles, locomotives, and aircraft were designed using dense metals with high strength capabilities. However, recent advancements in material science have enabled fiber-reinforced composites to replace traditional metals because of higher strength-to-weight ratios [1-3]. For instance, aluminum has traditionally been one of the most common metals used in the aerospace industry, but its usage dropped from $50 \%$ in the Boeing 777 aircraft to only $20 \%$ in the Boeing 787 [1]. The advantages that fiber reinforced composite materials have over traditional metal materials include: (1) light weight, (2) high stiffness and strength, (3) corrosion resistance, and (4) design flexibility. These attributes have been embraced by the automotive industry, which has increased its use of fiber-reinforced composite materials to improve fuel efficiency and reduce greenhouse gas emissions.

Among all of the different types of reinforcements utilized on a commercial scale, $65 \%$ of the revenue generated by the sale of fiber reinforced materials comes from glass fiber [4]. In 2020, the global glass fiber reinforced composite market is expected to grow to about 60 billion dollars [5]. Glass fiber is especially attractive as a reinforcement for composites because of its low cost, superior mechanical and physical properties (e.g., stiffness and strength, impact resistance, stability, and durability). The tensile modulus and the strength of E-glass fiber are around $72 \mathrm{GPa}$ and $3.5 \mathrm{GPa}$, respectively. This outperforms aluminum with a tensile modulus of $68.9 \mathrm{GPa}$ and tensile strength of $310 \mathrm{MPa}[6,7]$.

Thermotropic liquid crystalline polymers (TLCPs) are another type of reinforcement that is being extensively studied and used in both academia and industry $[8,9]$. Tremendous efforts have been made 
toward the development of TLCPs that exhibit high modulus and strength coupled with outstanding melt processability [8,10-12]. The drawn TLCP filaments display a modulus of up to $100 \mathrm{GPa}$ and tensile strength of about 1.5 GPa, which is comparable to the properties of E-glass fiber [13].

Both glass fiber and TLCP have excellent mechanical performance, high strength-to-weight ratio, and chemical resistance, but glass fiber is still a more attractive reinforcement choice over TLCP for three major reasons. First, TLCPs are more expensive than glass fiber. Depending on the grade of TLCP, the cost may range from eight to 12 dollars per pound [14]. Second, glass fiber has a higher tensile strength than TLCPs, especially when the TLCP is not generated using the fiber spinning or strand extrusion process. The full reinforcing potential of the TLCP fiber cannot be achieved under other processing techniques. Finally, glass fiber reinforced composites have lower mechanical anisotropy than their TLCP-filled counterparts. This is primarily due to the TLCP fibrils being created in situ under strong unidirectional elongation and shear flow [15].

One of the advantages of using TLCPs in reinforcing thermoplastic materials is the processability. It is well known that the incorporation of glass fibers into thermoplastics results in a substantial increase in viscosity, which gives rise to the difficulty in processing and high energy consumption [8]. During the processing of a TLCP composite melt, rigid chain TLCP molecules adopt highly oriented states relative to the partially oriented flexible chain molecules displayed by conventional thermoplastics [16]. Therefore, the melt viscosity of TLCP reinforced composites become much lower than that of glass-filled composites, leading to more facile processing. In addition, the surface smoothness of TLCP reinforced composites is greater than that of composites reinforced by glass fiber only [17]. The higher surface smoothness is related to the diameter of TLCP fibrils, which is one order of magnitude less than glass fiber. Additionally, the density of TLCP is around $1.4 \mathrm{~g} / \mathrm{cm}^{3}$, which is about half the density of E-glass fiber $\left(2.58 \mathrm{~g} / \mathrm{cm}^{3}\right)[7,18]$. The composite parts that utilize TLCP exhibit a lower weight than those of glass fiber, making the TLCP composite an attractive material, specifically for transportation applications. Finally, the recyclability of the TLCP composite has been found to be superior to glass-filled systems [19]. TLCP is able to regenerate a highly oriented molecular structure during the reprocessing while glass fiber would suffer severe fiber breakage during the recycling process.

To capitalize on the advantages of using TLCPs and glass fibers, composites consisting of both TLCPs and glass fiber as reinforcements in thermoplastics have been studied [20-25]. The in situ hybrid composite consists of three components: microscopic TLCP fibrils, macroscopic conventional fibers (e.g., glass and carbon fiber), and the matrix polymer [25]. Bafna et al. [23] reported the use of glass fiber and TLCP reinforcements to enhance the mechanical properties and reduce the mechanical anisotropy of in situ TLCP composites with polyetherimide (PEI) as the matrix material. Tensile and flexural moduli increased and the anisotropy reduced with increasing glass fiber content. Furthermore, the creep performance of PEI composites improved when TLCP and glass fiber were blended together. Another study looked to combine the advantages of short fiber composites and the TLCP composite. He et al. [25] investigated the mechanical, rheological, and morphological properties of hybrid in situ carbon fiber or glass fiber/TLCP composite systems. Improvement in tensile and flexural properties, lower melt viscosity, and more oriented fibers in the flow direction have been observed.

Although composite materials have a variety of advantages, one of the major challenges for fiber reinforced composites is their recyclability. The disposal of composite waste in an environmentally friendly manner is a crucial task to our society. Typically, fiber-reinforced composite materials are very difficult and energy intensive to recycle due to the nature of heterogeneity, technology limitations, high recycling cost, and low quality of recycled products. More restrictive environmental legislation drives the market toward recycling and reusing fiber reinforced composites. There are three major recycling methods to reclaim fiber reinforced composites: (1) thermal process, (2) solvolysis, and (3) mechanical recycling [26-29]. Mechanical recycling has less environmental impact, can recover both fiber and matrix polymer, and requires no use of solvents compared to thermal and solvent methods [30]. Mechanical recycling uses the principles of shredding or crushing the composite part into small particulates and then feeding these into a manufacturing machine to produce recycled parts. 
The recycled composites have very limited applications. Usually, the recycled composites, acting as "filler", are blended with virgin materials to make a product with similar performance as new "virgin" parts. The incorporation level of the recycled composites is usually no more than $10 \mathrm{wt} \%$ to minimize the negative impact from the recycled materials [30].

Mechanical recycling is considered environmentally friendly and cost-effective. However, the application of this method is hindered because the recycling process reduces the performance of subsequent composite parts. Extensive investigations have been carried out on the influence of mechanical recycling on the properties of glass or carbon fiber reinforced composites [31-34]. The mechanical properties of fiber reinforced composites decreased significantly after mechanical recycling, which is mainly due to fiber attrition during the recycling process. The need for developing a recyclable and high-performance composite is becoming extremely urgent.

Previous work has explored the effect of mechanical recycling on the properties of TLCP and glass fiber reinforced polypropylene [19]. The results illustrated that the TLCP composite had superior recyclability relative to that of its glass fiber reinforced counterpart. It is of great interest to determine whether there exists a formulation of TLCP, glass fiber, and matrix polymer that may be mechanically recycled without compromising the mechanical performance of the subsequent composite part. The objective of this work was to utilize glass fiber and TLCP to develop a recyclable and high-performance in situ polypropylene-based hybrid composite. The in situ hybrid composites were mechanically recycled once by injection molding and grinding processes. The processing temperature was optimized through rheological analyses to improve the processability and reduce the thermal degradation of polypropylene. The optimal formulation of glass fiber and TLCP enables the best combination of high recyclability, high mechanical properties, and low mechanical anisotropy of the hybrid composite.

\section{Materials and Methods}

\subsection{Materials}

The thermotropic liquid crystalline polymer (TLCP) used in this study, trade name Vectra B950 and made by Celanese (Florence, KY, USA), is an aromatic poly(ester-co-amide) composed of 6-hydroxy-2-naphthoic acid (60 mol\%), terephthalic acid (20 mol\%), and aminophenol (20 mol\%). The melting point of Vectra $\mathrm{B} 950$ is around $280^{\circ} \mathrm{C}$ [35]. The long glass fiber (GF) reinforced polypropylene was provided by SABIC (Ottawa, IL, USA) as $8.0 \mathrm{~mm}$ long pellets with a reinforcement loading of $50 \mathrm{wt} \%$. The diameter of the glass fiber is around $17 \mu \mathrm{m}$. The unfilled matrix polypropylene (PP), catalog name Pro-fax 6523, was purchased from LyondellBasell (Houston, TX, USA) and has a melt flow rate of $4.0 \mathrm{~g} / 10 \mathrm{~min}$ at $230{ }^{\circ} \mathrm{C} \mathrm{[36].}$

\subsection{Melt Compounding and Recycling of Hybrid Composites}

There were four combinations of the glass fiber and TLCP composite used in this study. These composites were designated as 30GF/PP, 20GF10TLCP/PP, 10GF20TLCP/PP, and 30TLCP/PP. The number before the component represents the weight percent of that particular reinforcement in the composite. For instance, 20GF10TLCP/PP means that the composite consists of $20 \mathrm{wt} \%$ glass fiber, $10 \mathrm{wt} \% \mathrm{TLCP}$, and $70 \mathrm{wt} \%$ polypropylene. The weight fraction of reinforcement in each composite was kept at $30 \mathrm{wt} \%$. To prepare the hybrid composites, the materials (e.g., TLCP, $50 \mathrm{wt} \%$ GF/PP, and $\mathrm{PP})$ were dried in a vacuum oven at $80^{\circ} \mathrm{C}$ for $24 \mathrm{~h}$. A single screw extruder with a 1-inch diameter screw and L/D ratio of 24 was used for compounding the TLCP and PP at $290{ }^{\circ} \mathrm{C}$. The extrudate was cooled down in a water bath and pelletized. The TLCP/PP and GF/PP pellets were injection molded (BOY 35E) into end-gate plaques to form the pristine hybrid composite. The pristine hybrid composites were shredded by a granulator (Cumberland/John Brown D-99050). The recycled hybrid composites were prepared by injection molding the shredded materials. The injection molding temperature was optimized at $305{ }^{\circ} \mathrm{C}$ based on rheological analyses. 


\subsection{Rheological Measurements of Polypropylene, TLCP, and Hybrid Composite}

An ARES-G2 rheometer with $25 \mathrm{~mm}$ parallel plates was used to investigate the viscoelastic properties of TLCP at four different experimental temperatures: $290,300,305$, and $310{ }^{\circ} \mathrm{C}$. All work was completed under a nitrogen atmosphere unless expressly stated as otherwise. Each sample was equilibrated to the experimental temperature for $5 \mathrm{~min}$. First, pure TLCP pellets were loaded directly into the rheometer and then tested using a shear step strain at a strain of $0.5 \%$ [37]. The relaxation modulus $(G(t))$ at each temperature was plotted against time. Further experimentation on the pure TLCP pellets included running a small amplitude oscillatory shear (SAOS) frequency sweep per temperature to obtain the complex viscosity, storage modulus, and loss modulus. Next, virgin PP material was first tested using SAOS rheology under time sweep mode at each temperature. The complex viscosity of PP was tracked as a function of time per temperature. Finally, all the compositions of recycled $\mathrm{GF} / \mathrm{TLCP} / \mathrm{PP}$ hybrid materials were used to measure the complex viscosity for each composition using the SAOS frequency sweep at $305^{\circ} \mathrm{C}$.

\subsection{Mechanical Properties}

Rectangular bars with dimensions of $75.0 \times 8.0 \times 1.5 \mathrm{~mm}$ were cut from the injection molded end-gated plaques of pristine and recycled hybrid composites in the flow direction and perpendicular to flow direction (transverse direction). For the flow direction, three strips were cut from one plaque from one edge of the plaque to the middle. The tensile properties of this plaque in the flow direction were the average properties of the three rectangular bars. At least five plaques for each composition were tested to obtain the average tensile properties. For the transverse direction, one strip was cut from the middle of the plaque and the tensile properties of each hybrid composite were the average properties of at least five plaques. All tensile properties of each material were measured using an Instron uniaxial tensile tester (Model 4204) with a $5 \mathrm{kN}$ load cell. The tensile strains of the specimen were measured with an extensometer (MTS 634.12). The cross-head speed was set at $1.27 \mathrm{~mm} / \mathrm{min}$.

\subsection{Differential Scanning Calorimetry (DSC) Characterization}

A DSC (TA Instruments Discovery) was used to examine the thermal properties of TLCP. Under a nitrogen atmosphere, a sample was subjected to a heat/cool/heat cycle. The material was first equilibrated at $50^{\circ} \mathrm{C}$ for $5 \mathrm{~min}$ and then heated up to $320^{\circ} \mathrm{C}$ at $10{ }^{\circ} \mathrm{C} / \mathrm{min}$. The materials were cooled down to $50^{\circ} \mathrm{C}$ at $-10^{\circ} \mathrm{C} / \mathrm{min}$ and then heated back to $320^{\circ} \mathrm{C}$ at $10^{\circ} \mathrm{C} / \mathrm{min}$. The melting temperature $\left(T_{\mathrm{m}}\right)$ was determined by the TA Instruments TRIOS software.

\section{Results and Discussion}

\subsection{Optimization of the Injection Molding Temperature}

To generate the in situ TLCP/glass fiber/polypropylene composites, the processing temperature has to be optimized using a series of rheological analyses. One advantage of blending TLCPs with other thermoplastics is the reduction in melt viscosity, which results in an improvement of the polymer blend's processability. TLCPs have lower melt viscosity when compared to many thermoplastics, and to take advantage of this, thermal and rheological properties of TLCPs need to be examined. The TLCP used in this study has a melting point around $280^{\circ} \mathrm{C}$ [35]. The rheological properties of TLCP above its melting point are critical in the processing of this material. Transient behaviors of TLCPs are related to the rigid TLCP molecules and domain structure [37,38]. The transient responses of pure TLCP at various test temperatures, following step strain were measured, as shown in Figure 1. The relaxation modulus $(G)$ is plotted against time on the log-log scale. At the testing temperatures below $305{ }^{\circ} \mathrm{C}$, the relaxation modulus decreases gradually over time, producing a long relaxation tail. This is graphically demonstrated by the relaxing curves at 290 and $300{ }^{\circ} \mathrm{C}$. On the other hand, the relaxation modulus $(\mathrm{G})$ sharply dropped when the temperature was equal and above $305^{\circ} \mathrm{C}$. It is speculated that the slow decay of the relaxation modulus at low temperature is due to the presence of 
unmelted crystals in the TLCP [37]. As the temperature further increased, TLCP crystals change to a liquid phase, causing the long relaxation tail to disappear, as seen by a dramatic drop in the relaxation modulus at the temperatures of 305 and $310^{\circ} \mathrm{C}$.

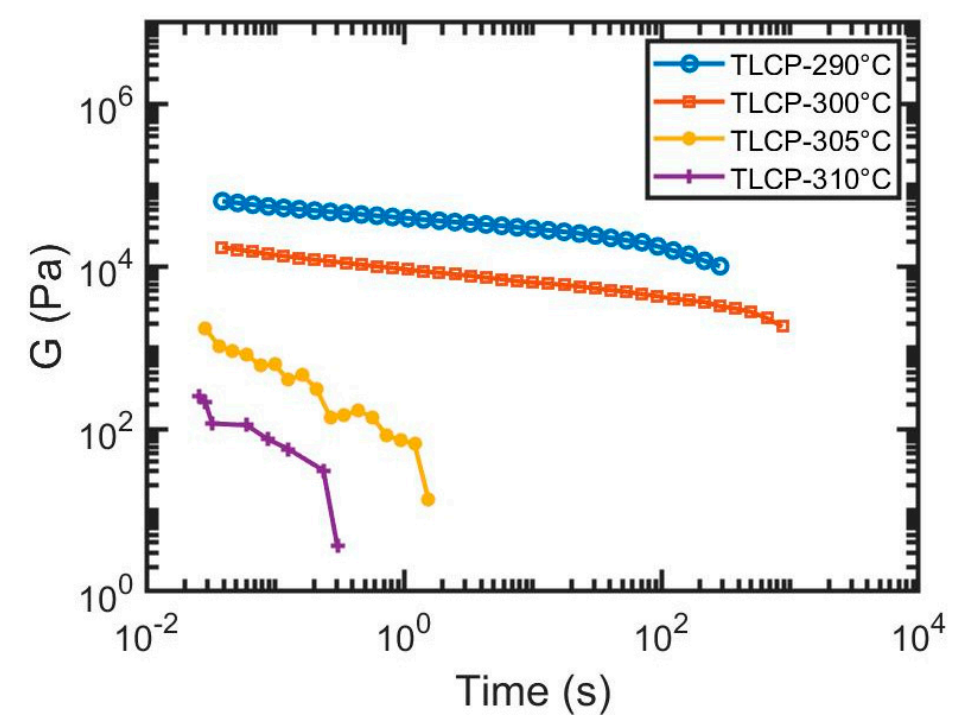

Figure 1. Stress relaxation of pure TLCP following a step shear strain at different test temperatures.

The complex viscosity $\left(\left|\eta^{*}\right|\right)$ of pure TLCP was measured using a rheometer in the frequency sweep mode. Figure 2 illustrates the complex viscosity of TLCP as a function of frequency for each experimental temperature. At 290 and $300^{\circ} \mathrm{C}$, the $\left|\eta^{*}\right|$ is more than an order of magnitude higher than the complex viscosity of TLCP at 305 and $310^{\circ} \mathrm{C}$, suggesting the TLCP has greater resistance to flow at lower temperatures. This further reinforces the idea that at low temperatures, there may be unmelted TLCP crystals. The TLCP melt exhibits a weak dependence between the complex viscosity and frequency at a temperature of $305^{\circ} \mathrm{C}$ and above. On the other hand, the relationship between complex viscosity and frequency at 290 and $300^{\circ} \mathrm{C}$ unveils a stronger correlation with the change of angular frequency. TLCPs usually exhibit three distinct regions of shear viscosity in which the first reflects a shear thinning behavior at low shear rates, followed by a Newtonian plateau, and eventually finishes with another shear thinning region at high shear rates [39]. In between the frequency range of $1-500 \mathrm{rad} / \mathrm{s}$, the Newtonian region was not seen for the temperature at 290 and $300{ }^{\circ} \mathrm{C}$, instead, the TLCP showed shear thinning behavior over the entire frequency sweep range. Only the Newtonian plateau and first shear thinning region were observed at $305^{\circ} \mathrm{C}$ and $310^{\circ} \mathrm{C}$, which is probably due to the angular frequency not being low enough. Since the complex viscosities of TLCP at 305 and $310^{\circ} \mathrm{C}$ almost overlap with each other, the viscosity of TLCP is not very sensitive to the changes in temperature in this temperature region. As the lowest complex viscosity of TLCP at all frequencies was exhibited at the temperature of 305 and $310^{\circ} \mathrm{C}$, the ideal processing temperature of TLCP blends would have to be equal to or higher than $305^{\circ} \mathrm{C}$ to reduce the viscosity during processing. 


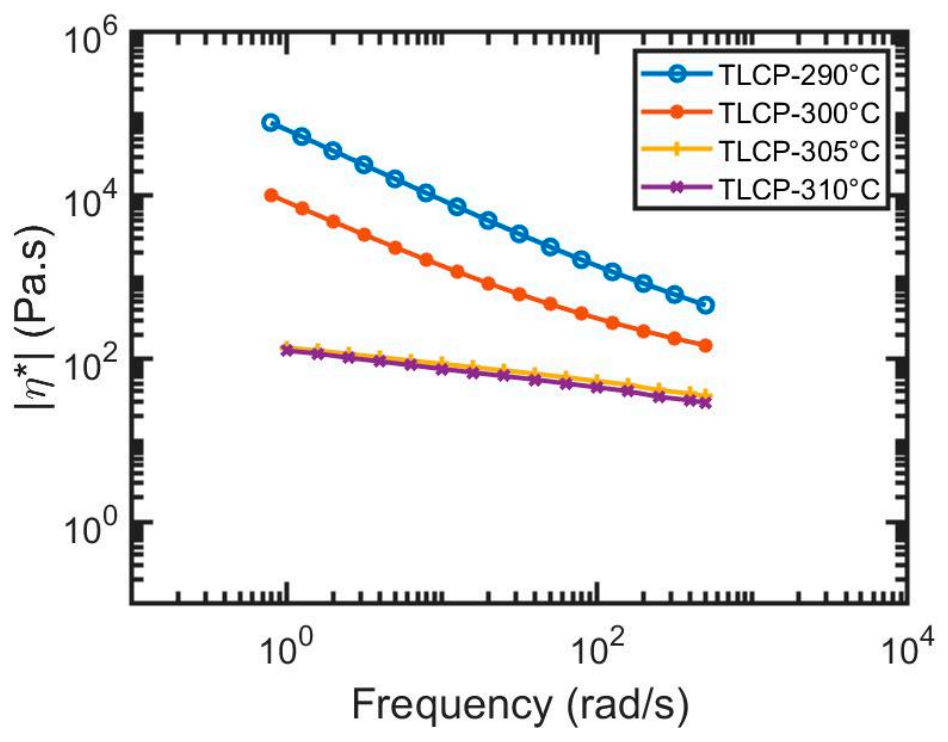

Figure 2. Complex viscosity of TLCP at temperatures from 290 to $310^{\circ} \mathrm{C}$.

The viscoelastic properties of pure TLCP at different temperatures were studied using oscillatory shear rheology. Figure 3 illustrates the change of storage $\left(G^{\prime}\right)$ and loss $\left(G^{\prime \prime}\right)$ moduli of TLCP as the function of angular frequency at varying operational temperatures. Storage modulus and loss modulus measure the stored energy and energy dissipated as heat, respectively. At $290^{\circ} \mathrm{C}$, the storage modulus was higher than the loss modulus over the entire frequency range, suggesting that the TLCP exhibits a solid-like character. After a $10{ }^{\circ} \mathrm{C}$ increase, the curves for $\mathrm{G}^{\prime}$ and $\mathrm{G}^{\prime \prime}$ crossover at $200 \mathrm{rad} / \mathrm{s}$. The crossover frequency characterizes the transition of a polymer melt from the elastic (solid-like) to the viscous (liquid-like) state. At $305^{\circ} \mathrm{C}$ and above, the $G^{\prime \prime}$ is higher than $G^{\prime}$ at all angular frequencies, indicating that the TLCP behaves like a viscous liquid. The $G^{\prime \prime}>G^{\prime}$ over the entire frequency range is probably due to the complete melt of TLCP crystals. The transitioning effect observed from the dramatic change of viscoelastic properties of TLCP with an increase in the testing temperature reinforces the notion that the existence of TLCP crystals significantly impacts the rheological behavior of TLCP.

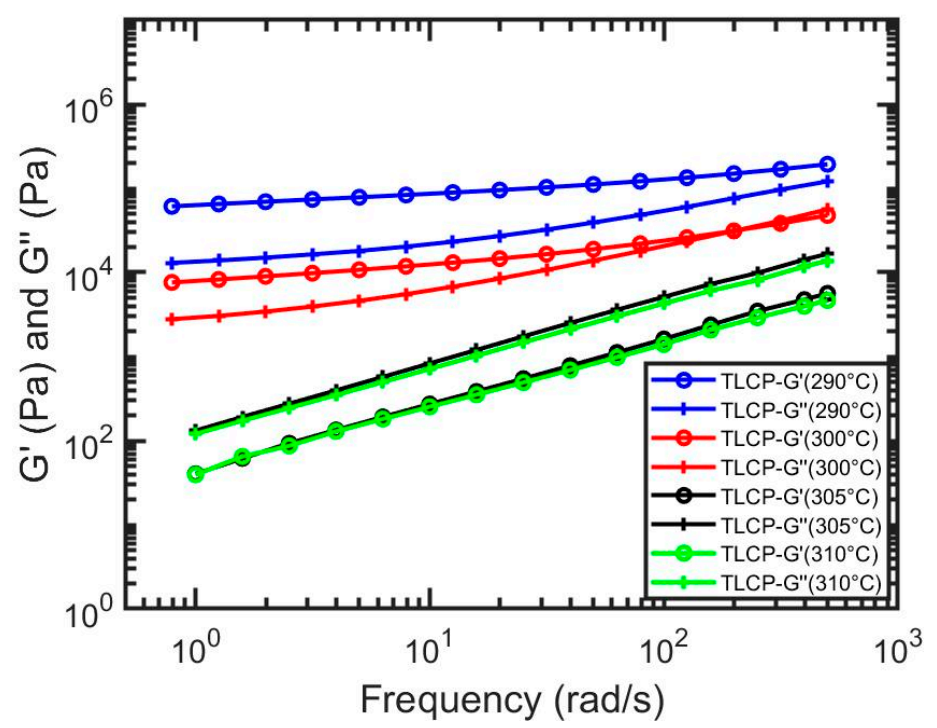

Figure 3. Storage modulus and loss modulus of TLCP at different temperatures above its melting point. 
A differential scanning calorimeter (DSC) was utilized to study the melting behavior of pure TLCP and to confirm any residual crystals of TLCP at temperatures above $280^{\circ} \mathrm{C}$. Two distinct transition phases were observed during the melting of TLCP, as shown by the two peaks in the DSC heating scan in Figure 4. The first peak was observed at around $280{ }^{\circ} \mathrm{C}$ and the second peak was observed around $297^{\circ} \mathrm{C}$. The different crystal structures develop during the process, leading to the mesophase transition of TLCP [40]. Literature reports state that the melting point of TLCP is around $280^{\circ} \mathrm{C}$ [35]. Several studies have successfully melt processed the PP with TLCP between 285 to $300{ }^{\circ} \mathrm{C}$, resulting in improved mechanical performance [35,41,42]. Nevertheless, to utilize the low viscosity effect of TLCP, the processing temperature must be high enough to melt all the TLCP crystals. Thus, the melting endotherm ends around $305{ }^{\circ} \mathrm{C}$, which confirms that the TLCP crystals have completely melted and shows consistency with the results obtained from the rheological analyses.

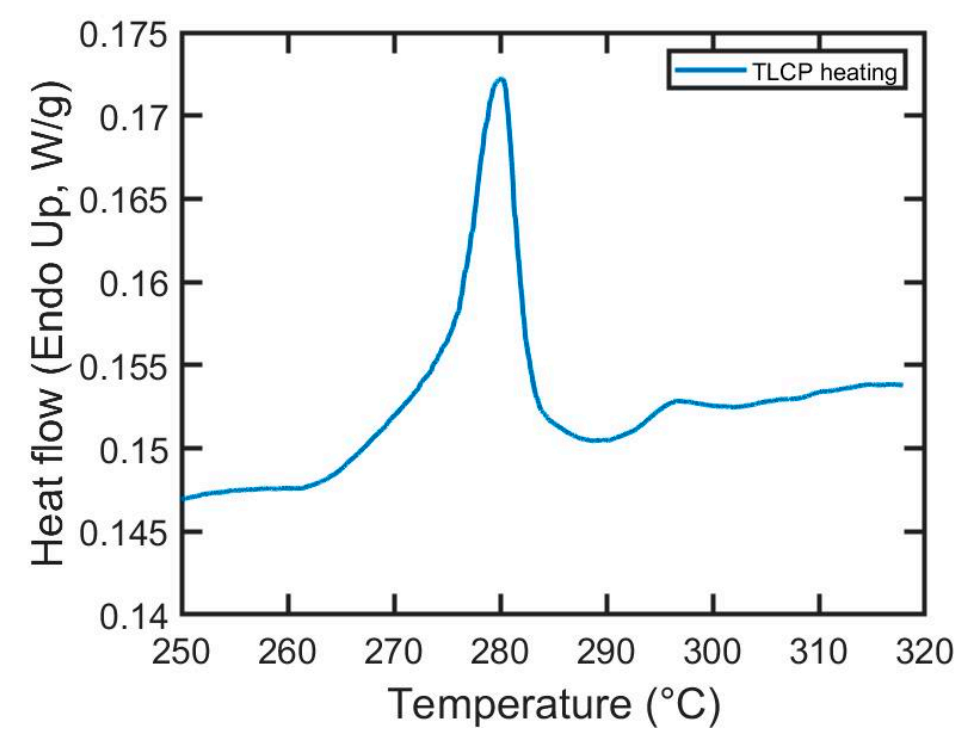

Figure 4. DSC heating scan of the TLCP material with the heating rate of $10^{\circ} \mathrm{C} / \mathrm{min}$.

Before processing the in situ hybrid GF/TLCP/PP composite, the PP used as the matrix of the composite needs to be tested to make sure it can withstand the high temperatures for processing. The high processing temperature improves the processability of the polymer blend, but also raises a concern regarding the thermal degradation of the polypropylene. The thermal stability of polypropylene was measured using the isothermal time sweep rheological test. Figure 5 shows the complex viscosity $\left(\left|\eta^{*}\right|\right)$ of polypropylene as a function of time at different experimental temperatures. The isothermal rheological tests were carried out under a nitrogen atmosphere to simulate the nitrogen purge hopper used during the injection molding process. The overall residence time exposed to high temperature for processing was around $240 \mathrm{~s}$.

During this time, the viscosities of polypropylene decreased by about $14.6 \%$ at $290{ }^{\circ} \mathrm{C}$ and $42.9 \%$ at $310^{\circ} \mathrm{C}$. Polypropylene undergoes severe thermal degradation at $310{ }^{\circ} \mathrm{C}$. The degradation rate of polypropylene at $300{ }^{\circ} \mathrm{C}$ and $305^{\circ} \mathrm{C}$ in the nitrogen environment was much lower than at $310{ }^{\circ} \mathrm{C}$, where the complex viscosity dropped around $26.7 \%$ at $305^{\circ} \mathrm{C}$ (Figure 5). Therefore, to achieve better processability and reduce the thermal degradation of the polypropylene, $305^{\circ} \mathrm{C}$ was selected as the processing temperature for injection molding of the hybrid composite materials. 


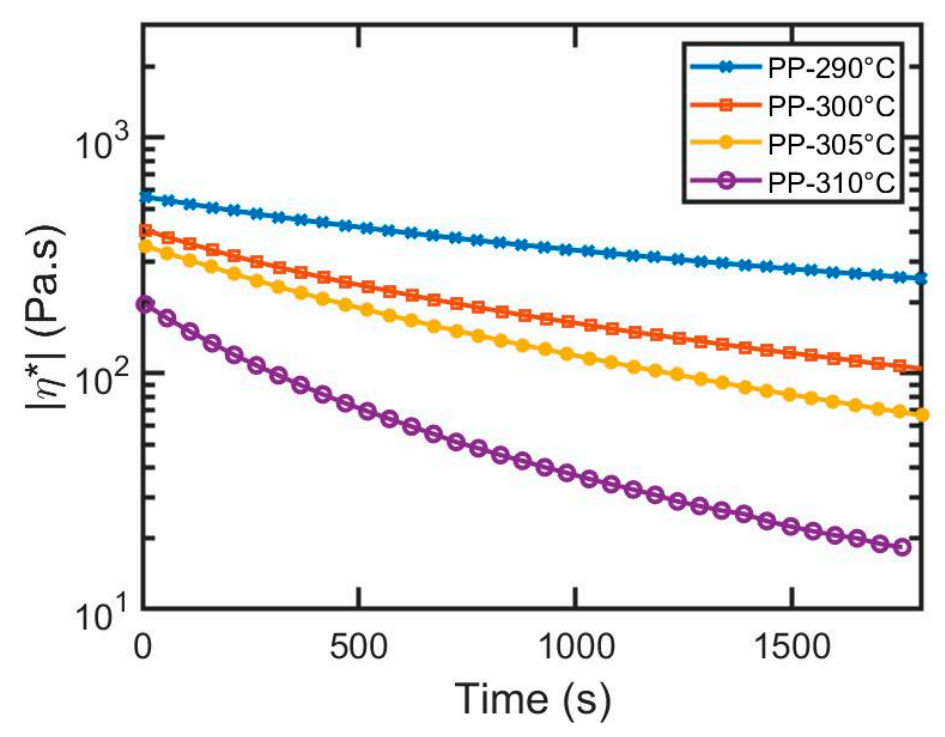

Figure 5. Thermal stability of polypropylene at various temperatures (isothermal time sweep mode).

\subsection{Rheology of the In Situ TLCP/GF Hybrid Composites}

To characterize the rheological properties of the recycled hybrid composite, small amplitude oscillatory shear (SAOS) frequency sweep tests were carried out at $305^{\circ} \mathrm{C}$. The complex viscosity was plotted against the angular frequency for each formation of the recycled hybrid composite, as indicated in Figure 6. Hybrid composites with varying TLCP and glass fiber compositions displayed dramatic differences in rheological behaviors. At low frequencies, the viscosity increased with increasing glass fiber concentration. When glass fiber was used as the sole reinforcement in the composite, the viscosity jumped two-fold compared to its TLCP counterpart at $305^{\circ} \mathrm{C}$. At low frequencies, the complex viscosity plateau was not observed for the glass-filled hybrid composite, but rather the complex viscosity appreciably increased with the decrease in angular frequency. This response of the composite to low frequency was due to the fiber-fiber and glass-fiber matrix interactions in glass-filled systems [43]. As frequency increases, these interactions are interrupted, and the complex viscosity of glass-filled composite decreases dramatically. On the other hand, TLCP/PP showed overall weak dependence between complex viscosity and angular frequency. The incorporation of glass fibers into the TLCP/PP composite significantly increased the complex viscosity of the hybrid composite. Especially in the low angular frequency, the complex viscosity of the hybrid composite increased exponentially with the addition of glass fiber. The hybrid composite with a higher concentration of TLCP showed significant reduction in viscosity, thereby confirming that TLCP reduced the viscosity of polymer blends [8]. Not only did the TLCP increase the processability of the GF/PP composite by lowering the melt viscosity, but it also mitigated the fiber breakage issue by reducing stresses acting on the fibers by the matrix polymer. In turn, diminishing fiber breakage leads to higher mechanical performance of the composites [44-46].

One concern regarding this rheological test is the thermal degradation of polypropylene at $305{ }^{\circ} \mathrm{C}$, which decreases the complex viscosity over time. This may cause the ill-defined viscosity data at high frequency (rheological test sweeps the frequency from low to high), but this frequency sweep test provides a method to qualify the benefit of a higher TLCP concentration, resulting in the lower viscosity of a hybrid composite. 


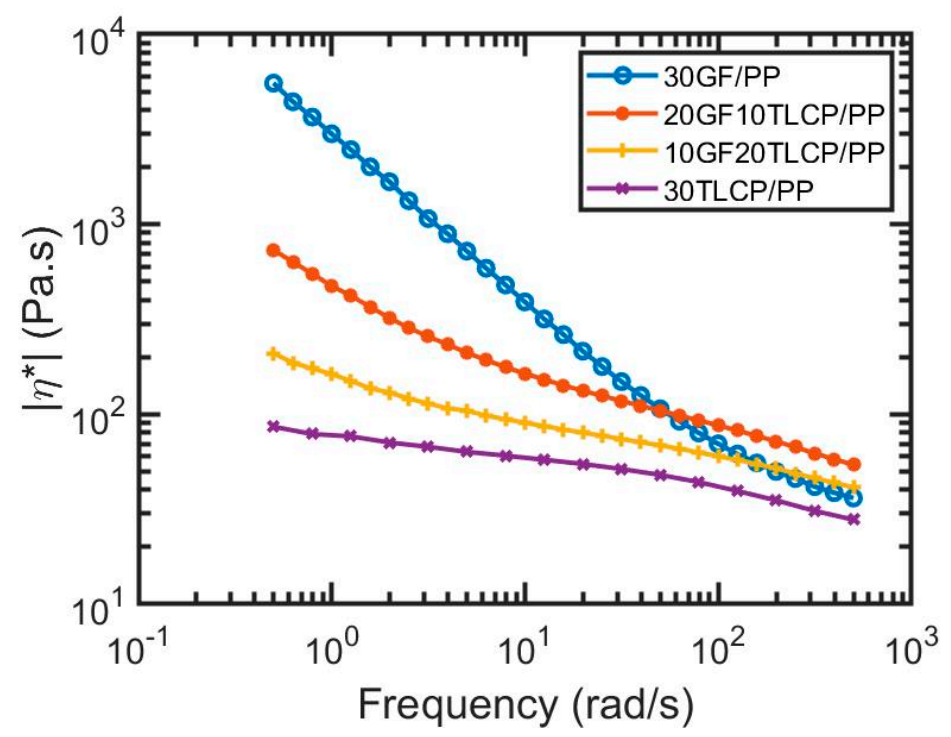

Figure 6. SAOS frequency sweep of hybrid composites at $305^{\circ} \mathrm{C}$ in a nitrogen atmosphere.

\subsection{Mechanical Properties of the Recycled TLCP/GF Hybrid Composite}

The first injection molded samples were defined as pristine materials (blue). The recycled composites (red) were obtained by grinding the pristine materials and re-injection molding into end-gated plaques. The tensile properties of each hybrid composite are depicted in Figures 7-9. The modulus of pristine $30 \mathrm{wt} \% \mathrm{GF} / \mathrm{PP}$ was $5.07 \mathrm{GPa}$, and the modulus of pristine TLCP/PP was about 3.83 GPa. The lower modulus of the TLCP blend was speculated to have originated from the injection molding process, which is unable to achieve high elongational deformation. The tensile modulus of $26 \mathrm{wt} \% \mathrm{TLCP} / \mathrm{PP}$ is reported to be $13.5 \mathrm{GPa}$ when the sample is prepared by strand extrusion [47]. By replacing $10 \mathrm{wt} \%$ of the TLCP with glass fiber, the tensile modulus improved by $7.4 \%$. The tensile modulus of the hybrid composite fell between the $30 \mathrm{wt} \%$ GF/PP and TLCP/PP. To determine the effect of mechanical recycling on the hybrid composite materials, the pristine composites were ground and injection molded into end-gated plaques. After recycling, the tensile modulus of the GF/PP composite dropped to $4.87 \mathrm{GPa}$ while the tensile modulus of TLCP/PP remained the same. The major factor for the decrease in the GF/PP composite modulus was the fiber length attrition during the recycling process [34]. The TLCP was able to regenerate the TLCP fibrils during the mold filling process, and the TLCP-filled composites maintained their mechanical performance after mechanical recycling. In addition, the recyclability of a glass-filled composite was improved with the presence of TLCP, as seen with the 20GF10TLCP/PP hybrid composite only losing $4.1 \%$ of its modulus after recycling.

The tensile strengths of the pristine and recycled hybrid composites are shown in Figure 8. The tensile strength of pristine GF/PP was much higher than that of TLCP/PP because the tensile strength of the TLCP ( 0.5 GPa) was lower than the tensile strength of GF ( 3.5 GPa). The same difference in the properties of the composites was also expected to be seen $[47,48]$. By adding glass fiber into the TLCP blend, the tensile strength was significantly enhanced. Replacing $10 \mathrm{wt} \%$ TLCP with glass fiber enabled the improvement of the tensile strength from 36.8 to 50.0 MPa. Mechanical recycling imposes different degrees of impact on the tensile strength of hybrid composites. The tensile strength of $30 \mathrm{wt} \% \mathrm{GF} / \mathrm{PP}$ dropped from 71.5 to $61.7 \mathrm{MPa}$ after recycling, but there was only a $9.6 \%$ decrease in the tensile strength of 20GF10TLCP/PP. Just as for the tensile modulus, this was due to the severe fiber length attrition during the blending and grinding processes. The higher content of glass fiber and higher melt viscosity accelerated the fiber breakage during processing. The short glass fiber composite showed lower mechanical properties than the long glass fiber composite [46]. The higher content of TLCP in the hybrid composite lessened the decrease in the mechanical properties of the composites after recycling. 


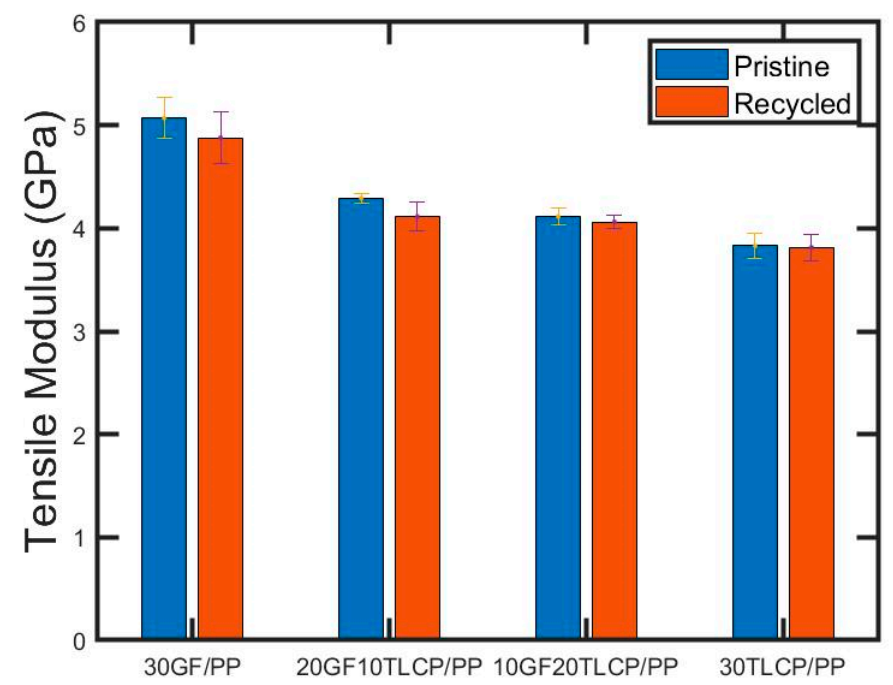

Figure 7. Tensile modulus of pristine and recycled hybrid composites in the flow direction.

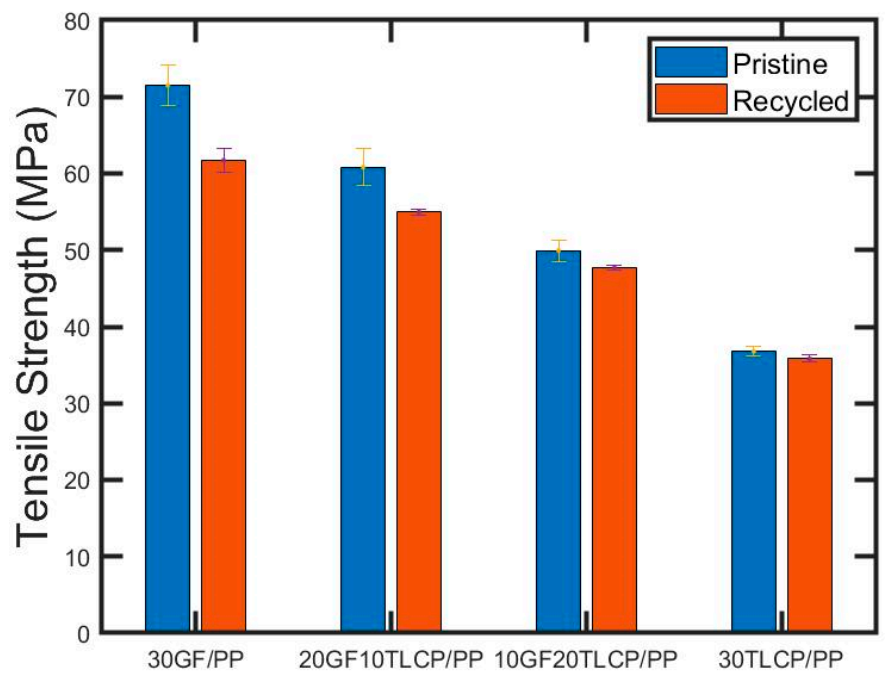

Figure 8. Tensile strength of pristine and recycled hybrid composites in the flow direction.

The mechanical properties of the hybrid composites in the transverse-to-flow direction were measured and are shown in Figure 9. The rectangular bar was cut from injection-molded, end-gated plaques in the direction perpendicular-to-flow in order to obtain the performance of the hybrid composites in the transverse-to-flow direction. Similar to the mechanical behaviors in the flow direction, the tensile properties of TCLP/PP were lower than the GF/PP due to the combining effect of different mechanical properties of the pure materials used and processing methods. The addition of $10 \mathrm{wt} \%$ glass fiber improved the tensile modulus of TLCP/PP from 1.8 to $2.5 \mathrm{GPa}$. In terms of recyclability, the large decrease in the mechanical properties of GF/PP after recycling can be seen in Figure 9. The extent of the decrease in the mechanical properties of the composites after recycling in the transverse-to-flow direction was mitigated by replacing glass fiber with TLCP. The tensile strength of 10GF20TLCP/PP only decreased from 21.4 to $20.2 \mathrm{MPa}$ after mechanical recycling, while the $30 \mathrm{wt} \% \mathrm{TLCP} / \mathrm{PP}$ composite exhibited little or no change in the tensile modulus and strength in the transverse-to-flow direction. Hybrid composite formulations provide the balance between recyclability and mechanical performance. 

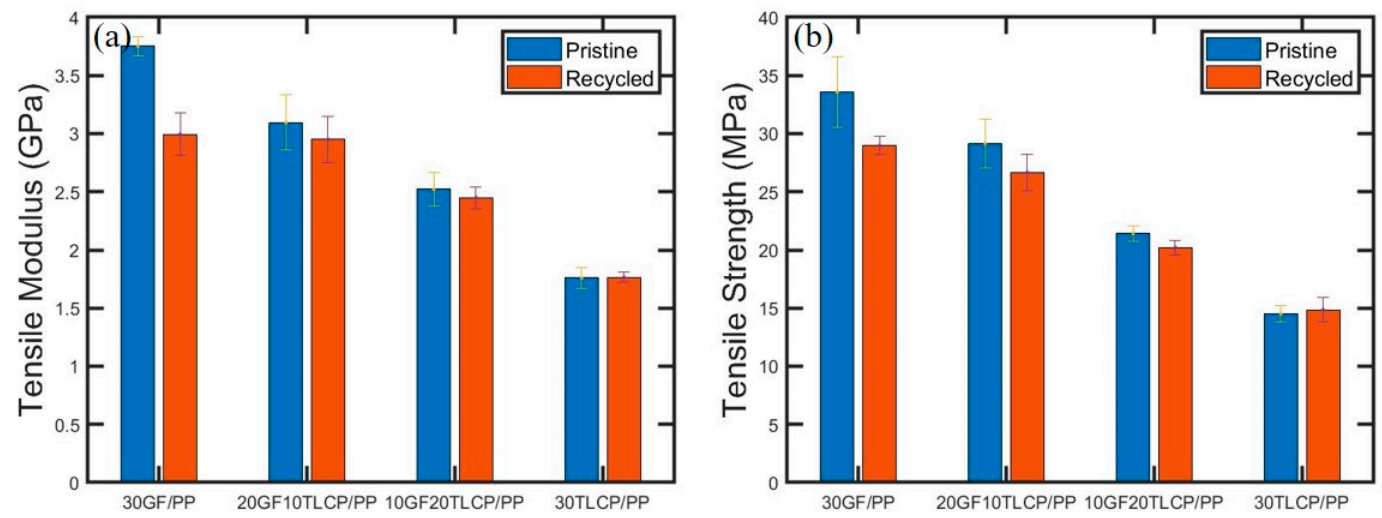

Figure 9. Tensile properties of hybrid composites in the transverse-to-flow direction. (a) Tensile modulus; (b) tensile strength.

\subsection{Mechanical Anisotropy of the Hybrid TLCP/GF Composite}

Mechanical anisotropy is an important parameter to evaluate the performance of the composite material. Table 1 illustrates the tensile modulus of the composites in the flow and transverse-to-flow directions as well as the mechanical anisotropy. Mechanical anisotropy is the ratio of the property in the flow direction over the property in the transverse-to-flow direction. Several studies have been published about the mechanical anisotropy of injection-molded composites $[23,49,50]$.

TLCP composites have significantly higher mechanical anisotropy than their glass-filled counterparts, which is caused by TLCP fibrils being generated in the direction of elongational flow developed at the melt front. The transverse-to-flow direction has less TLCP fibrils than the flow direction. With a higher content of TLCP in the blend, the degrees of mechanical anisotropy increased rapidly [50]. This is one of the major limitations when using in situ TLCP composites. For glass-filled composites, the glass fibers can be aligned in both flow and transverse-to-flow directions through flow kinematics during the mold filling process, leading to less mechanical anisotropy. As indicated in Table 1, the modulus of $30 \mathrm{wt} \% \mathrm{TLCP} / \mathrm{PP}$ was 3.83 and 1.76 in the flow and transverse-to-flow directions, respectively. The anisotropy for the TLCP/PP composite was calculated to be 2.2, but the mechanical anisotropy of glass fiber reinforced polypropylene was only 1.35. Therefore, the anisotropy of the TLCP-filled composite can be lessened with the addition of glass fiber, which is demonstrated in Table 1, where we can see that the 10GF20TLCP/PP hybrid composite had its mechanical anisotropy reduced by $26 \%$. The hybrid composites effectively reduced the mechanical anisotropy of the in situ TLCP composite.

Table 1. Mechanical anisotropy of the hybrid composites.

\begin{tabular}{cccc}
\hline Material & Modulus (GPa) Flow & Modulus (GPa) Transverse & Mechanical Anisotropy \\
\hline 30GF/PP & 5.07 & 3.75 & 1.35 \\
20GF10TLCP/PP & 4.25 & 3.10 & 1.37 \\
10GF20TLCP/PP & 4.11 & 2.52 & 1.63 \\
30TLCP/PP & 3.83 & 1.76 & 2.2 \\
\hline
\end{tabular}

\subsection{Recyclability of the Hybrid TLCP/GF Composite Material}

To evaluate the recyclability of each composite material, the mechanical properties of the recycled composite were compared against the pristine counterpart. The normalized values of the tensile properties of the hybrid composites are presented in Figure 10. The normalized values were obtained by dividing the tensile properties of the recycled composites by their pristine material properties. For the tensile properties of the hybrid composites in the flow direction, the normalized values increased with increasing weight fraction of TLCP, suggesting an improvement in the recyclability with the presence 
of TLCP (Figure 10a). The $30 \mathrm{wt} \% \mathrm{GF} / \mathrm{PP}$ only retained $86 \%$ of its tensile strength after recycling, and 10GF20TLCP/PP retained $96 \%$ of its tensile strength compared to the pristine composite. The tensile modulus in the flow direction was not significantly impacted by mechanical recycling. The different impact of recycling on tensile modulus and strength is due to the different sensitivity of each property to the change in fiber length [46].

Figure $10 \mathrm{~b}$ exhibits the normalized tensile properties of the hybrid composite in the transverse-to-flow direction. The properties follow a similar trend as before where properties increased with increasing TLCP concentration. The tensile modulus of GF/PP dropped significantly after recycling, which may be due to the joint influence of fiber breakage and decrease of fiber orientation in the transverse-to-flow direction. In the injection molding process, long fiber polymer blends have a larger core region where fibers are randomly oriented [51,52]. These effects may lead to large drops in the tensile modulus of GF/PP in the transverse-to-flow direction. The normalized values of tensile properties are significantly influenced by the content of glass fiber and TLCP in both the flow and transverse-to-flow directions. The recycling process has a greater impact on the tensile strength of composite materials than their tensile modulus in both the flow and transverse-to-flow directions.
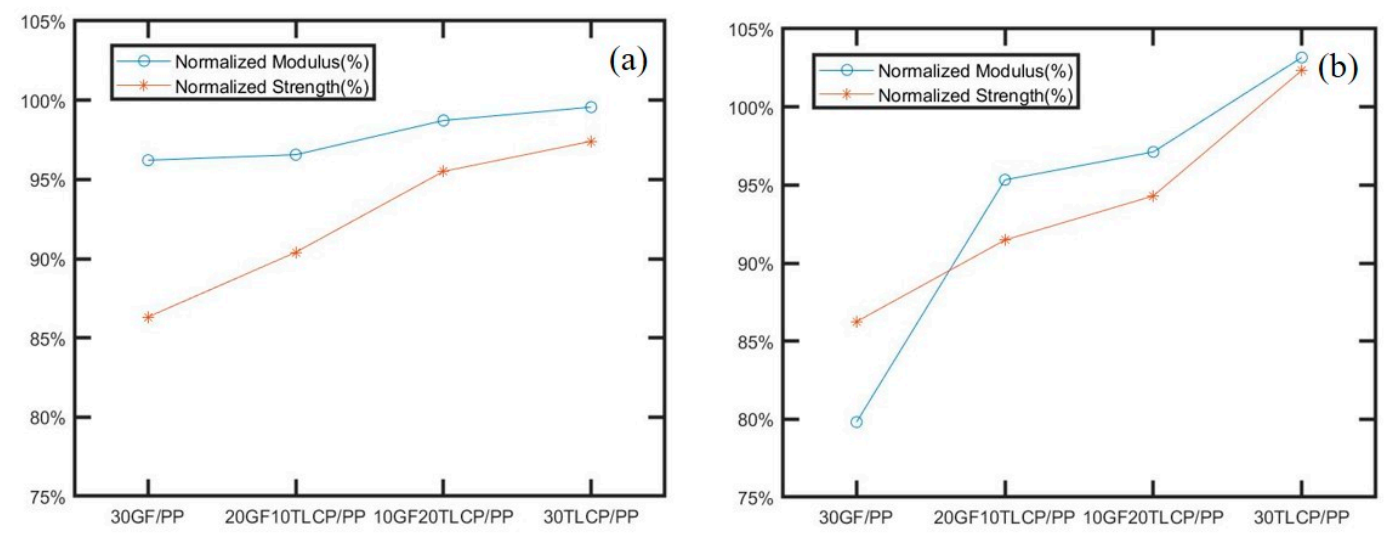

Figure 10. Percentage of mechanical properties of the recycled composite to pristine composite in (a) flow direction and (b) transverse-to-flow directions.

The knock-down (KD) factor is used to quantify the degree of recyclability of a hybrid composite where a low KD factor means better recyclability. The knock-down factor for a composite is determined by comparing the property of recycled material relative to its pristine material [53]. The KD factor is defined by the following equation:

$$
K D=\left(1-\frac{P_{r}}{P_{v}}\right) \times 100(\%)
$$

where $P_{r} / P_{v}$ is the ratio of recycled material to the pristine material property. Table 2 shows the KD factor of each composite in the flow direction. The KD factor of tensile modulus and strength for glass fiber reinforced polypropylene was 3.8 and 13.7, respectively. The KD factor decreased in value with increasing TLCP concentration, thereby confirming that the higher TLCP weight fraction in a TLCP/GF hybrid composite gives rise to greater recyclability. Composites with a KD factor less than five are typically considered to be within design limits for various applications where the recycled part can be used to replace that made of pristine material [53]. The formulation of $10 \mathrm{wt} \%$ glass fiber and $20 \mathrm{wt} \% \mathrm{TLCP}$ resulted in the creation of a recyclable and high-performance hybrid material. Based on Figure 10, the formulation that contains a ratio of 2 to 1 or higher TLCP to glass fiber will yield a recyclable hybrid composite. 
Table 2. The knock down (KD) factor of the in situ hybrid composite.

\begin{tabular}{ccc}
\hline Material & KD (Modulus) & KD (Strength) \\
\hline 30GF/PP & 3.8 & 13.7 \\
20GF10TLCP/PP & 2.4 & 9.6 \\
10GF20TLCP/PP & 1.3 & 4.5 \\
30TLCP/PP & 0.4 & 2.6 \\
\hline
\end{tabular}

\section{Conclusions}

It has been found that the combination of TLCP fibrils and glass fiber can result in a high-performance and recyclable hybrid composite. The processing temperature of the injection-molding process was determined by rheological analyses and DSC. To provide a low viscosity blend to ensure that all the TLCP crystals were melted and to reduce excessive thermal degradation of polypropylene, the composites were processed at $305^{\circ} \mathrm{C}$. In situ hybrid composites were successfully generated at the optimized processing temperature. Due to the hybrid nature of the glass fiber and TLCP, the in situ hybrid composite exhibited balanced performance with respect to processability, mechanical properties, and recyclability. The $10 \mathrm{wt} \%$ glass fiber and $20 \mathrm{wt} \%$ TLCP hybrid composite material was the best formulation of the hybrid composite because it lowered the melt viscosity, thereby increasing its processability while maintaining high tensile properties, lowered mechanical anisotropy, and increased recyclability of the TLCP/GF hybrid composite.

Author Contributions: Conceptualization, T.C.; Methodology, T.C.; Validation, T.C.; Formal analysis T.C.; Investigation T.C., D.K. and L.J.; Writing-original draft preparation, T.C.; Writing-review and editing, D.K., L.J., D.A.O. and D.G.B.; Supervision, D.A.O. and D.G.B.; Funding acquisition, D.A.O. All authors have read and agreed to the published version of the manuscript.

Funding: The funding is from General Motor with Project Number GAC3053.

Acknowledgments: Support from General Motor (GM) is gratefully acknowledged. The authors would like to thank Celanese and SABIC for providing materials.

Conflicts of Interest: The authors declare no conflict of interest.

\section{References}

1. Lu, K. The future of metals. Science 2010, 328, 319-320. [CrossRef] [PubMed]

2. Rajak, D.K.; Pagar, D.D.; Menezes, P.L.; Linul, E. Fiber-reinforced polymer composites: Manufacturing, properties, and applications. Polymers 2019, 11, 37. [CrossRef]

3. Clyne, T.; Hull, D. An Introduction to Composite Materials; Cambridge University Press: Cambridge, UK, 2019.

4. Report, M.A. Fiber Reinforced Polymer (FRP) Composites Market Analysis by Fiber Type. Available online: https://www.grandviewresearch.com/industry-analysis/fiber-reinforced-polymer-frp-compositesmarket (accessed on 29 June 2020).

5. Report, M.R. GFRP Composites Market by End-Use Industry. Available online: https://www.marketsandmarkets. com/Market-Reports/glass-fiber-reinforced-plastic-composites-market-142751329.html (accessed on 30 June 2020).

6. ASM Aerospace Specification Metals Inc. Aluminum 6061-t6. Available online: http://asm.matweb.com/ search/SpecificMaterial.asp?bassnum=MA6061T6 (accessed on 5 June 2020).

7. Prashanth, S.; Subbaya, K.; Nithin, K.; Sachhidananda, S. Fiber reinforced composites-A review. J. Mater. Sci. Eng. 2017, 6, 1-6.

8. Weiss, R.A.; Wansoo, H.; Nicolais, L. Novel reinforced polymers based on blends of polystyrene and a thermotropic liquid-crystalline polymer. Polym. Eng. Sci. 1987, 27, 684-691. [CrossRef]

9. Chae, H.G.; Kumar, S. Rigid-rod polymeric fibers. J. Appl. Polym. Sci. 2006, 100, 791-802. [CrossRef]

10. Wang, X.-J.; Zhou, Q.-F. Liquid Crystalline Polymers; World Scientific Publishing Company: Singapore, 2004.

11. Donald, A.M.; Windle, A.H.; Hanna, S. Liquid Crystalline Polymers; Cambridge University Press: Cambridge, UK, 2006.

12. Qian, C.; Mansfield, C.D.; Baird, D.G. Extrusion blow molding of polymeric blends based on thermotropic liquid crystalline polymer and high density polyethylene. Int. Polym. Process. 2017, 32, 112-120. [CrossRef] 
13. Kalfon-Cohen, E.; Marom, G.; Wachtel, E.; Pegoretti, A. Characterization of drawn monofilaments of liquid crystalline polymer/carbon nanoparticle composites correlated to nematic order. Polymer 2009, 50, 1797-1804. [CrossRef]

14. Collier, M.C. Reclamation and Reprocessing of Thermotropic Liquid Crystalline Polymer from Composites of Polypropylene Reinforced with Liquid Crystalline Polymer. Ph.D. Thesis, Virginia Tech, Blacksburg, VA, USA, 1998.

15. Handlos, A.A.; Baird, D.G. Processing and associated properties of in-situ composites based on thermotropic liquid-crystalline polymers and thermoplastics. J. Macromol. Sci-Rev. Macromol. Chem. Phys. 1995, C35, 183-238. [CrossRef]

16. Collyer, A.A. Liquid Crystal Polymers: From Structures to Applications; Springer Science \& Business Media: Berlin, Germany, 2012; Volume 1.

17. Baird, D.G.; Huang, J. Injection molding of polypropylene reinforced with thermotropic liquid crystalline polymer microfibrils. Part II: Effect of impact toughening. J. Inject. Mold. Technol. 2002, 6, 107.

18. Williams, D. Applications for thermotropic liquid crystal polymer blends. Adv. Polym. Technol. 1990, 10, 173-184. [CrossRef]

19. Chen, T.; Mansfield, C.D.; Ju, L.; Baird, D.G. The influence of mechanical recycling on the properties of thermotropic liquid crystalline polymer and long glass fiber reinforced polypropylene. Compos. Part B Eng. 2020, 200, 108316. [CrossRef]

20. Yu, X.B.; Wei, C.; Xu, D.; Lu, C.H.; Yu, J.H.; Lu, S.R. Wear and mechanical properties of reactive thermotropic liquid crystalline polymer/unsaturated polyester/glass fiber hybrid composites. J. Appl. Polym. Sci. 2007, 103, 3899-3906. [CrossRef]

21. Yu, X.; Chun, W.; Lu, S.; Yu, J.; Deng, X.; Lu, C. Preparation and mechanical properties of tlcp/up/gf in-situ hybrid composites. T. Nonferr. Metal. Soc. 2006, 16, s529-s533. [CrossRef]

22. Huang, J.; Baird, D.G. Injection molding of polypropylene reinforced with thermotropic liquid crystalline polymer microfibrils. Part III: Combination of glass and tlcp. J. Inject. Mold. Technol. 2002, 6, 187.

23. Bafna, S.S.; Desouza, J.P.; Sun, T.; Baird, D.G. Mechanical-properties of in-situ composites based on partially miscible blends of glass-filled polyetherimide and liquid-crystalline polymers. Polym. Eng. Sci. 1993, 33, 808-818. [CrossRef]

24. He, J.S.; Zhang, H.Z.; Wang, Y.L. In-situ hybrid composites containing reinforcements at two orders of magnitude. Polymer 1997, 38, 4279-4283. [CrossRef]

25. He, J.S.; Wang, Y.L.; Zhang, H.Z. In situ hybrid composites of thermoplastic poly(ether ether ketone), poly(ether sulfone) and polycarbonate. Compos. Sci. Technol. 2000, 60, 1919-1930. [CrossRef]

26. Pickering, S.J. Recycling technologies for thermoset composite materials-Current status. Compos. Part A Appl. Sci. Manuf. 2006, 37, 1206-1215. [CrossRef]

27. Piñero-Hernanz, R.; Dodds, C.; Hyde, J.; García-Serna, J.; Poliakoff, M.; Lester, E.; Cocero, M.J.; Kingman, S.; Pickering, S.; Wong, K.H. Chemical recycling of carbon fibre reinforced composites in nearcritical and supercritical water. Compos. Part A Appl. S. Compos. 2008, 39, 454-461. [CrossRef]

28. Cunliffe, A.M.; Jones, N.; Williams, P.T. Pyrolysis of composite plastic waste. Environ. Technol. 2003, 24, 653-663. [CrossRef]

29. Howarth, J.; Mareddy, S.S.; Mativenga, P.T. Energy intensity and environmental analysis of mechanical recycling of carbon fibre composite. J. Clean. Prod. 2014, 81, 46-50. [CrossRef]

30. Oliveux, G.; Dandy, L.O.; Leeke, G.A. Current status of recycling of fibre reinforced polymers: Review of technologies, reuse and resulting properties. Prog. Mater. Sci. 2015, 72, 61-99. [CrossRef]

31. Chrysostomou, A.; Hashemi, S. Influence of reprocessing on properties of short fibre-reinforced polycarbonate. J. Mater. Sci. 1996, 31, 1183-1197. [CrossRef]

32. Kuram, E.; Ozcelik, B.; Yilmaz, F. The influence of recycling number on the mechanical, chemical, thermal and rheological properties of poly(butylene terephthalate)/polycarbonate binary blend and glass-fibre-reinforced composite. J. Thermoplast. Compos. Mater. 2016, 29, 1443-1457. [CrossRef]

33. Colucci, G.; Ostrovskaya, O.; Frache, A.; Martorana, B.; Badini, C. The effect of mechanical recycling on the microstructure and properties of pa66 composites reinforced with carbon fibers. J. Appl. Polym. Sci. 2015, 132, 9. [CrossRef]

34. Eriksson, P.A.; Albertsson, A.C.; Boydell, P.; Prautzsch, G.; Manson, J.A.E. Prediction of mechanical properties of recycled fiberglass reinforced polyamide 66. Polym. Compos. 1996, 17, 830-839. [CrossRef] 
35. Postema, A.R.; Fennis, P.J. Preparation and properties of self-reinforced polypropylene liquid crystalline polymer blends. Polymer 1997, 38, 5557-5564. [CrossRef]

36. Lyondellbasell Pro-Fax 6523 Technical Data Sheet. Available online: https://www.lyondellbasell.com/en/ polymers/p/Pro-fax-6523/cca46629-99c9-4596-8390-83b67fd362ff (accessed on 6 June 2020).

37. Done, D.; Baird, D.G. Transient flow of thermotropic liquid-crystalline polymers in step strain experiments. J. Rheol. 1990, 34, 749-762. [CrossRef]

38. Viola, G.G.; Baird, D.G. Studies on the transient shear-flow behavior of liquid-crystalline polymers. J. Rheol. 1986, 30, 601-628. [CrossRef]

39. Cocchini, F.; Nobile, M.R.; Acierno, D. Transient and steady rheological behavior of the thermotropic liquid-crystal copolymer 73/27 hba hna. J. Rheol. 1991, 35, 1171-1189. [CrossRef]

40. Chung, T.S.; Cheng, M.; Pallathadka, P.K.; Goh, S.H. Thermal analysis of vectra b950 liquid crystal polymer. Polym. Eng. Sci. 1999, 39, 953-962. [CrossRef]

41. Datta, A.; Baird, D.G. Compatibilization of thermoplastic composites based on blends of polypropylene with 2 liquid-crystalline polymers. Polymer 1995, 36, 505-514. [CrossRef]

42. Qin, Y.; Brydon, D.L.; Mather, R.R.; Wardman, R.H. Fibers from polypropylene and liquid-crystal polymer blends: 3. A comparison of polyblend fibers containing vectra-a900, vectra-b950 and rodrun-lc3000. Polymer 1993, 34, 3597-3604. [CrossRef]

43. Shenoy, A.V. Rheology of Filled Polymer Systems; Springer Science \& Business Media: Berlin, Germany, 2013.

44. Vonturkovich, R.; Erwin, L. Fiber fracture in reinforced thermoplastic processing. Polym. Eng. Sci. 1983, 23, 743-749. [CrossRef]

45. Zhang, G.; Thompson, M.R. Reduced fibre breakage in a glass-fibre reinforced thermoplastic through foaming. Compos. Sci. Technol. 2005, 65, 2240-2249. [CrossRef]

46. Thomason, J.L. The influence of fibre length and concentration on the properties of glass fibre reinforced polypropylene: 5. Injection moulded long and short fibre pp. Compos. Part A Appl. Sci. Manuf. 2002, 33, 1641-1652. [CrossRef]

47. Baird, D.G.; Robertson, C.G.; De Souza, J.P. Liquid Crystalline Polymer-Reinforced Thermoplastic Fibers. U.S. Patent 5,834,560, 10 November 1998.

48. Mallick, P.K. Fiber-Reinforced Composites: Materials, Manufacturing, and Design; CRC Press: Boca Raton, FL, USA, 2007.

49. Mortazavian, S.; Fatemi, A. Effects of fiber orientation and anisotropy on tensile strength and elastic modulus of short fiber reinforced polymer composites. Compos. Part B Eng. 2015, 72, 116-129. [CrossRef]

50. Mehta, A.; Isayev, A.I. Rheology, morphology, and mechanical characteristics of poly(etherether ketone)-liquid crystal polymer blends. Polym. Eng. Sci. 1991, 31, 971-980. [CrossRef]

51. Toll, S.; Andersson, P.O. Microstructure of long-fiber and short-fiber reinforced injection molded polyamide. Polym. Compos. 1993, 14, 116-125. [CrossRef]

52. Thomason, J.L. Micromechanical parameters from macromechanical measurements on glass reinforced polyamide 6,6. Compos. Sci. Technol. 2001, 61, 2007-2016. [CrossRef]

53. Eriksson, P.A.; Albertsson, A.C.; Boydell, P.; Manson, J.A.E. Durability of in-plant recycled glass fiber reinforced polyamide 66. Polym. Eng. Sci. 1998, 38, 348-356. [CrossRef]

(C) 2020 by the authors. Licensee MDPI, Basel, Switzerland. This article is an open access article distributed under the terms and conditions of the Creative Commons Attribution (CC BY) license (http://creativecommons.org/licenses/by/4.0/). 